Illinois State University

ISU ReD: Research and eData

Theses and Dissertations

10-3-2016

\title{
Measurement Invariance and Psychometric Properties of Career Indecision Profile-65 Scores: College Student and Non-College Samples
}

Casey J. Zobell

Illinois State University, czobell@ilstu.edu

Follow this and additional works at: https://ir.library.illinoisstate.edu/etd

Part of the Psychology Commons, and the Statistics and Probability Commons

\section{Recommended Citation}

Zobell, Casey J., "Measurement Invariance and Psychometric Properties of Career Indecision Profile-65 Scores: College Student and Non-College Samples" (2016). Theses and Dissertations. 643.

https://ir.library.illinoisstate.edu/etd/643

This Thesis is brought to you for free and open access by ISU ReD: Research and eData. It has been accepted for inclusion in Theses and Dissertations by an authorized administrator of ISU ReD: Research and eData. For more information, please contact ISUReD@ilstu.edu. 


\title{
MEASUREMENT INVARIANCE AND PSYCHOMETRIC PROPERTIES OF \\ CAREER INDECISION PROFILE-65 SCORES: COLLEGE STUDENT \\ AND NON-COLLEGE SAMPLES
}

\author{
Casey J Zobell
}

50 Pages

This thesis reports the results of a study conducted to examine psychometric properties of Career Indecision Profile-65 scores, including measurement invariance between college student and non-college samples. The responses of 529 college students and 472 non-college students to an online survey revealed that a four-factor structure fit the data in both samples well. Metric invariance was not supported. Six-week test-retest reliability was found to be high and in the expected range. The tendency to maximize was found to be correlated strongly with one of the four factors. This study furthered the psychometric research for the Career Indecision Profile-65 and found evidence to support its use in practice and further research. Further implications, as well as limitations and future directions are discussed.

KEYWORDS: Career Indecision, CIP-65, Measurement Invariance, College Students, Vocational Psychology. 


\section{MEASUREMENT INVARIANCE AND PSYCHOMETRIC PROPERTIES OF CAREER INDECISION PROFILE-65 SCORES: COLLEGE STUDENT AND NON-COLLEGE SAMPLES}

CASEY J ZOBELL

A Thesis Submitted in Partial Fulfillment of the Requirements for the Degree of MASTER OF SCIENCE

Department of Psychology

ILLINOIS STATE UNIVERSITY 
Copyright 2016 Casey J Zobell 


\section{MEASUREMENT INVARIANCE AND PSYCHOMETRIC PROPERTIES OF CAREER INDECISION PROFILE-65 SCORES: COLLEGE STUDENT AND NON-COLLEGE SAMPLES}

CASEY J ZOBELL

COMMITTEE MEMBERS:

Margaret M. Nauta, Chair

Matthew Hesson-McInnis 


\section{ACKNOWLEDGMENTS}

I would like to thank my committee, Drs. Margaret M. Nauta and Matthew HessonMcInnis for all of their guidance, knowledge, and insight. I would also like to thank my wonderful wife, Shannon, for her continual support, moving across the country with me, and sharing this adventure we call life. I would not be where I am today without my grandparents, who taught me the value of hard work and instilled in me a love for learning.

C. J Z. 


\section{CONTENTS}

\section{Page}

ACKNOWLEDGMENTS

CONTENTS

ii

TABLES

iv

CHAPTER I: INTRODUCTION

CHAPTER II: LITERATURE REVIEW

Previous Measurements of Career Indecision $\quad 4$

Meta-Analyses and Development of the CIP-167 and CIP-65 5

$\begin{array}{ll}\text { Characteristics of Psychometrically Sound Instruments } & 8\end{array}$

$\begin{array}{ll}\text { Reliability } & 8\end{array}$

Validity 9

$\begin{array}{ll}\text { Generalizability } & 10\end{array}$

$\begin{array}{ll}\text { Measurement Invariance } & 10\end{array}$

Evaluation of the Psychometric Properties of CIP-65 Scores 11

$\begin{array}{ll}\text { Purpose of this Study and Hypotheses } & 13\end{array}$

$\begin{array}{ll}\text { CHAPTER III: METHOD } & 20\end{array}$

$\begin{array}{ll}\text { Participants and Procedure } & 20\end{array}$

University Sample $\quad 21$

$\begin{array}{ll}\text { MTurk Sample } & 22\end{array}$

Comparison of University and MTurk Samples’ Demographics 23

$\begin{array}{ll}\text { Measures } & 24\end{array}$

$\begin{array}{ll}\text { Demographic Items } & 24\end{array}$ 
$\begin{array}{ll}\text { Career Indecision } & 24\end{array}$

Maximizing vs. Satisficing $\quad 25$

$\begin{array}{ll}\text { Screening Questions } & 26\end{array}$

$\begin{array}{ll}\text { Data Analyses } & 26\end{array}$

$\begin{array}{ll}\text { Assessing Model Fit } & 26\end{array}$

$\begin{array}{ll}\text { Assessing Measurement Invariance } & 27\end{array}$

$\begin{array}{ll}\text { CHAPTER IV: RESULTS } & 28\end{array}$

Correlations, Descriptive Statistics, and Internal Consistency 28

Replication in a University Sample $\quad 30$

Measurement Invariance: College Student and Non-College Samples 30

$\begin{array}{ll}\text { Test-Retest Reliability } & 35\end{array}$

Relation with Maximization 36

$\begin{array}{ll}\text { CHAPTER V: DISCUSSION } & 37\end{array}$

Significance of Measurement Invariance Results 37

Additional Psychometric Information about CIP-65 Scores 39

$\begin{array}{ll}\text { Implications for Practice } & 41\end{array}$

Limitations and Future Research Directions $\quad 42$

$\begin{array}{ll}\text { Conclusion } & 43\end{array}$

REFERENCES 


\section{TABLES}

Table

Page

1. Means, Standard Deviations, Cronbach's Alphas, and Correlations among CIP-65 Factor and MTS Scores for University and MTurk Samples

2. Measures of Fit

3. Within-Group Completely Standardized Loadings for the CIP-65 across Samples

4. Results of Metric Invariance Tests between University $(N=529)$ and MTurk $(N=472)$ Samples 


\section{CHAPTER I: INTRODUCTION}

Making decisions about one's vocation is often hard; few people avoid entirely the difficulties that go along with this decision-making. Career indecision has been of importance to researchers and practitioners for approximately the last 40 years and leads many to seek assistance with career decision-making. Understanding what factors contribute to career indecision and being able to dissect these sources in counseling is important because it better allows counselors to tailor their therapeutic approach.

Among the most common career interventions are administering and interpreting interest inventories such as the Strong Interest Inventory (Donnay, Morris, Schaubhut, \& Thompson, 2005; Brown \& Ryan Krane, 2000). These interventions are predicated on the assumption that clients struggling with career indecision lack information about themselves. These inventories have been shown to have modest-sized effects (Brown \& Ryan Krane, 2000), but because they are not large effects it is likely that career indecision involves more than lack of information. Several studies have been conducted to identify more definitively the other underlying factors of career indecision and develop measures to help counselors determine the degree to which they are causing problems for a client.

Although many measures of career indecision have been developed, their contributions to client improvement have been consistently small, and the underlying factors proposed by each differ dramatically. A meta-analytic study meant to renew interest in the field revealed over 50 factors that correlate with career indecision, resulting in a four-factor model of career indecision (Brown \& Rector, 2008). Brown and colleagues (2012) revised this four-factor model and used it to create a useful new measure of career indecision: the Career Indecision Profile-167 (CIP-167). Although valuable, the measure's length of 167 items deterred it from being widely used in 
practice. The instrument was therefore shortened and tested for structural integrity (Hacker, Carr, Abrams, \& Brown, 2013). The resulting 65-item measure was labeled the Career Indecision Profile-65 (CIP-65).

Some empirical support exists for the reliability and validity of the CIP-65's scores, but a more thorough evaluation of their psychometric properties needs to be conducted before the CIP65 's use in practice can be warranted. The purpose of this thesis was to conduct a more thorough evaluation of the CIP-65 by replicating the factor structure of the measure in U.S. college students, as well as to examine the measurement invariance in a previously uninvestigated, fundamentally different population: young adults not enrolled in college. I also hoped to help users evaluate the merits of the CIP-65 for use in practice and further research by assessing previously unexamined, yet potentially enlightening components of reliability and validity. 


\section{CHAPTER II: LITERATURE REVIEW}

The construct of career indecision is of interest to practitioners and researchers because many people feel unable to choose a career or vocation among myriad options, which leads many to seek help with this problem. Although career indecision is a seemingly straightforward construct, it has long been thought of as a complex, multidimensional construct, with few investigators reaching consensus on its nature. Career indecision can be defined generally as the state of being undecided regarding vocational interest, yet it also applies to a range of difficulties individuals might experience during the process of choosing a career path (Foley, Kelly, \& Hartman, 2006). Holland and Holland (1977) suggested that three types of people seek career indecision help from counselors: (a) individuals with information deficits, (b) individuals with interpersonal barriers and conflicts, and (c) individuals who suffer from anxiety and immaturity. In another early study, Salomone (1982) found that those seeking help for career indecision were chronically indecisive; their difficulties in choosing a career reflected a larger problem of indecision, anxiety, and dependency on others to provide information for them. Among the Big-5

personality traits, career indecision has been found to correlate positively with Neuroticism and to correlate negatively with conscientiousness (Kelly \& Pulver, 2003). An additional trait that has been predicted to correlate with career indecision is the tendency to maximize (Brown et al., 2012). Maximizers, as opposed to satisficers, tend to seek out many options and not settle for a less-than-perfect solution.

These two seminal studies suggest that 1) career indecision is caused by several psychological and contextual factors and 2) clients seeking help for this problem are far from uniform. Most of the research that has ensued has used these findings as a starting place to understand and adequately measure career indecision. Correlational, factor analytic, and cluster 
analytic studies have been conducted to understand further the factors that correlate with career indecision and uncover the underlying factors that comprise it. As a result, six notable instruments have emerged to measure this construct, including the instrument that is the focus of the present study - the Career Indecision Profile-65.

\section{Previous Measurements of Career Indecision}

Following factor analytic studies (e.g. Osipow, Carney, \& Barak, 1976) and the seminal research of Holland and Holland (1977) and Salomone (1982), the first measure of career indecision, the Career Decision Scale (Osipow, 1986) aimed both to measure overall levels of indecision and examine the underlying reasons for individuals' indecision. The measure's 16 items were split into four subscales: Lack of Structure and Confidence, Perceived External Barriers, Positive Choice Conflict, and Personal Conflict. In addition, two items were used to assess individuals' overall level of career indecision. Further research, however, has not provided support for the four-factor structure. As a result, only total scores for certainty and overall indecision are reported when the Career Decision Scale is used in practice and research (Brown \& Rector, 2008).

Soon after the Career Decision Scale was published, the Career Decision Profile (Jones, 1989) was created. Similar to the Career Decision Scale, the Career Decision Profile contains four subscales that assess reasons for respondents' career indecision difficulties: Knowledge about Occupations and Training, Self-Clarity, Decisiveness, and Career Choice Importance. In addition to the four-factor reason dimension, the Career Decision Profile contains decidedness and comfort dimensions. Internal consistency estimates are moderate, with the highest being .77 for Self-Clarity. The measure's four-factor structure has garnered considerable support (Jones, 1989). 
The third multidimensional career indecision measure to be published was the Career Factors Inventory (Chartrand, Robbins, Morrill, \& Boggs, 1990). Again, a four-factor structure was found that included two informational reasons of career indecision (Need for SelfInformation and Need for Career Information) and two affective reasons of career indecision (Generalized Indecisiveness and Career Choice Anxiety). Research has generally supported the factor structure but has suggested the combination of the informational subscales and affective subscales into two higher-order factors (Chartrand \& Nutter, 1996). Internal consistency estimates are relatively high, with the lowest being .79 for Generalized Indecisiveness. The Career Decision Difficulties Questionnaire (Gati, Krauzs, \& Osipow, 1996) contains three higher-order scales and ten subscales. The Lack of Readiness scale consists of three subscales: (a) Lack of Motivation, (b) Indecisiveness, and (c) Dysfunctional Myths. The Lack of Information scale consists of four subscales: (a) Lack of Knowledge about the Process, (b) Lack of Information about Self, (c) Lack of Information about Occupations, and (d) Lack of Information about Ways of Obtaining Additional Information. The Inconsistent Information Scale consists of three subscales: (a) Unreliable Information, (b) Internal Conflicts, and (c) External Conflicts. Internal consistency estimates range from .63 to .95 for the scores from higher-order scales and from .29 to .91 for the scores from the subscales. Subsequent confirmatory factor analyses have provided general support for the model, although some studies have shown subscales to load on different higher-order factors (Kelly \& Lee, 2002; Tien, 2005).

\section{Meta-Analyses and Development of the CIP-167 and CIP-65}

Two meta-analyses of career indecision interventions (Brown \& Ryan Krane, 2000; Whiston, Brecheisen, \& Stephens, 2003) showed that on average, clients only improve about a third of a standard deviation compared to control clients. Interventions for career indecision 
usually focus on anxiety, career self-efficacy, and family dynamics (Foley et al., 2006). Noting this modest effectiveness, Brown and Rector (2008) sought to revive research on the sources of career indecision by providing clarity and cohesiveness to the field, reasoning that interventions might be more effective if the "true" underlying factors were agreed upon. To accomplish this goal, the authors started by gathering over 50 variables that had been included in career indecision correlational research as well as variables that were theoretically assumed to contribute to indecision. They hypothesized that the myriad variables intercorrelate to form a few overarching sources of career decision-making difficulties. An interpretable four-factor model of career indecision was found using analyses from 28 published correlation matrices (Brown \& Rector, 2008).

The first factor was labeled Indecisiveness/Trait Negative Affect and is defined by both state and trait anxiety, low self-esteem, a fear of commitment, an external locus of control, and generalized indecisiveness. The second factor was labeled Lack of Information and is defined by a lack of both self and occupational information, as well as approach-approach conflict (conflict between two or more options). The third factor was labeled Interpersonal Conflicts and Barriers and is defined by external conflicts with significant others, external barriers, and situational constraints. The fourth factor was labeled Lack of Readiness and is defined by identity diffusion, a lack of self-clarity, immature career attitudes, unstable goals, and a lack of motivation.

In 2012, Brown and colleagues set out to provide additional support for the previously described four-factor model of career indecision at the primary and secondary data levels. In the first study, the authors created a 167-item measure based on items from subscales of instruments that had loaded saliently on one of the four factors in the Brown and Rector (2008) meta-analysis (primary data replication). This new measure was named the CIP-167. In a second study, the 
authors sought to use exploratory factor analysis to uncover the same four-factor model from two different models of career indecision: Gati and colleagues' (1996) cognitive model and a personality/ emotional model of career indecision, which hypothesizes that the three underlying factors of career indecision are a) pessimistic views, b) anxiety, and c) self and identity (Saka, Gati, \& Kelly, 2008). The authors reasoned that if similar factor structures could be found using meta-analytic analyses, primary, and secondary replication, it would suggest a universal representation of career indecision sources in college students.

At the primary data replication level, a four-factor solution was found that was similar to the meta-analytically derived solution. Two factors (Interpersonal Conflicts and Lack of Readiness were nearly identical to the factors of the same name found by Brown and Rector (2008), whereas the other two factors had notable differences. The Indecisiveness/Trait Negative Affect factor was relabeled as Neuroticism/Negative Affect because the items that loaded saliently on this factor were consistent with the definition of trait neuroticism (Costa \& McCrae, 1992). A more important difference was found on the Lack of Information factor, which was relabeled as Choice/Commitment Anxiety. Although all information-related items loaded on this factor, items related to the inability to make career decisions and narrow interests also loaded saliently. At the secondary data replication level, a three-factor solution was obtained that included factors indicating choice/commitment anxiety, interpersonal conflict, and neuroticism. Together, these studies provide evidence for a meaningful conceptualization of the sources of career indecision.

Although evidence to support the CIP-167 is robust, its length of 167 items makes it a deterrent to use in research or counseling. Although many instruments, like the Minnesota Multiphasic Personality Inventory-II (567 items; Tellegen \& Ben-Porath, 2011), that are 
commonly used in practice are longer, existing measures of career indecision are much shorter. For example, the longest commonly used measure of career indecision, the Career Decision Difficulties Questionnaire, consists of 34 items. Because of this, a shortened version of the CIP was created by using the items that loaded most strongly on their respective factors. The new 65item measure is known as the CIP-65 (Hacker, Carr, Abrams, \& Brown, 2013). Using confirmatory factor analysis, its factor structure was found to be the same as that of the longer measure from which it was derived. Equally important was the finding that neither a single factor model nor the four-factor model proposed by Brown and Rector (2008) fit the data as well as the four-factor model uncovered by Brown and colleagues (2012). To reiterate, the four underlying factors uncovered in both the CIP-167 and the CIP-65 are 1) Neuroticism/Negative Affect, 2) Choice/Commitment Anxiety, 3) Lack of Readiness, and 4) Interpersonal Conflicts.

\section{Characteristics of Psychometrically Sound Instruments}

When choosing instruments for research and practice, it is important to note the psychometric properties of the measures' scores. Validity and reliability are both important attributes. External validity, or generalizability, is especially desirable if the measure is to be used in a more diverse population than those on which it has previously been tested.

\section{Reliability}

Reliability is the property of consistency of a measure's scores (McBurney \& White, 2010). Two kinds of reliability are noteworthy: test-retest reliability and internal consistency. If a test has high test-retest reliability among a given population, it will give consistent scores across time within subjects, provided the subjects' "true" scores have not changed. For example, we can expect trait anxiety to have high test-retest reliability, but the same cannot be expected of state anxiety. Internal consistency concerns whether the items in a scale (or subscale) measure the 
same construct. An example of internal consistency is split-half reliability, which is calculated by dividing a measure into two halves and testing the within-person correlation between the halves. A more common measure of internal consistency is Cronbach's alpha, which can be thought of as the average of all possible split-half reliabilities.

\section{Validity}

Whereas reliability is an important attribute of the scores from psychological assessment instruments, it would be meaningless without validity. Tests are often described in terms of validity, but validity is not a characteristic of an assessment. A test cannot be valid; only the inferences made from it can be (Binning \& Barrett, 1989; Cronbach, 1970). On a related note, although there are many types of validity, it is a unitary concept. Put simply, if an assessment actually measures what it purports to measure, the inferences made from the results can be valid. There are several relevant forms of validity for psychometric instruments such as the CIP-65, including construct validity and criterion validity. Construct validity refers to the ability of the test to assess the underlying construct or attribute it is supposed to measure. Because constructs are not directly observable, evidence for construct validity is best observed by establishing convergent and discriminant validity. In short, results from the measurement should agree with other tests that purport to measure the same construct, and differ from the results of tests that measure dissimilar constructs.

Criterion validity refers to the ability of a test to predict the performance on a specific criterion. If the criterion is in the future, it is known as predictive validity; if the criterion is simultaneous, it is known as concurrent validity. For example, for a measure of career indecision to have both forms of criterion validity, it should accurately predict problems relevant to 
choosing a career both now and in the future (barring a personal revelation or the acquisition of additional, enlightening information).

\section{Generalizability}

A psychometric assessment should also possess external validity, or generalizability, if it is to be widely used in practice. For example, in creating a depression inventory that is to be administered across several ethnicities and socioeconomic statuses, a researcher would be unwise to collect data from only middle-class, White participants. As the consistency of a study's results increase across situations (e.g., location, time, demographic variables etc.), generalizability also increases. Generalizability is limited, then, when the results of an experiment do not replicate well to other samples or to other treatment conditions. A common way of assessing the generalizability of a measure is by conducting a measurement invariance study.

\section{Measurement Invariance}

The property of measurement invariance is a requirement before valid comparisons of group means can be made (Abrams et al., 2013). Three types of measurement invariance are relevant when measuring constructs among members of different groups: configural, metric, and scalar invariance. These types of invariance build upon each other. That is, metric invariance requires the conditions for configural invariance to be met, and scalar invariance requires the conditions for both configural and metric invariance to be met. Configural invariance is concerned with the overall factor structure. If configural invariance is established, metric invariance may be assessed. Metric invariance is concerned with the interpretation of test items across groups, that is, a lack of similar factor loadings between groups. Full metric invariance is very rare. It is usually acceptable if a small percentage of items show a lack of metric invariance. Last, if metric invariance is supported, scalar invariance may be assessed. If this type of 
invariance is found, individuals in different groups with the same mean score on a particular factor likely respond similarly to the test items that factor consists of (Vandenburg \& Lance, 2000). That is, the intercepts are equal. Two additional types of invariance, strict and equivalent, exist but both are extremely uncommon and rarely achievable. In addition to the requirements of the previous three types of measurement invariance, strict invariance requires residuals to be equal across groups, while equivalent invariance requires residuals and means to be equal across groups.

To clarify further, the following are hypothetical examples of the first three types of measurement invariance. If the same four factors of the CIP-65 were to emerge in collegestudent and non-college samples, the CIP-65 will be considered configurally invariant for those two groups. However, if in the non-college sample, a five-factor structure were to emerge (e.g., one factor has split into two), the CIP-65 would have configural variance for the two groups. If for both samples, the same four factors were to emerge and the individual items loaded equivalently within each factor, the CIP-65 would be considered to have metric invariance. Alternatively, if items load differently in at least one of the factors in the non-college sample, the CIP-65 would have metric variance for the two groups. Last, if for both samples, the same four factors emerged, the factor loadings were equivalent, and the intercepts were equal, the CIP-65 would be considered to have scalar invariance. If some intercepts were different in the noncollege sample, the CIP-65 would have scalar variance for the two groups.

\section{Evaluation of the Psychometric Properties of CIP-65 Scores}

Because the CIP-65 is a relatively new assessment, much is not known about its scores' psychometric properties. Most of what we do know, however, is promising. In previous studies, Cronbach's $\alpha$ estimates were all high, ranging from .88 for the Lack of Readiness scale to .97 for 
the Choice/Commitment Anxiety scale (Hacker et al., 2013). The authors also showed the measure's scores to exhibit construct validity among college students by comparing students enrolled in career planning courses to those not enrolled. Career planning students scored significantly lower on decidedness and higher on three out of the four subscales (with no difference being found on the Interpersonal Conflict scale) than those not enrolled in such courses. In addition, all four subscales' scores correlate significantly with self-reported levels of decidedness (Hacker et al., 2013).

Since its creation in 2013, the CIP-65's factor structure has been replicated using multiple-group confirmatory factor analyses (CFAs) in four international samples: Icelandic (Abrams et al., 2013), French-speaking, Italian (Carr et al., 2013), and South Korean (Abrams, Lee, Brown \& Carr, 2014). In the Icelandic study, data were collected from a total of 395 participants in two upper secondary schools (18-20 year old students) and the largest university in Iceland. The four-factor structure was found to be equivalent to the U.S. sample, but the factor loadings were not invariant for two factors (Choice/Commitment Anxiety and Interpersonal Conflicts). This difference might indicate that these two factors hold different meanings in the two countries (Abrams et al., 2013).

Carr and colleagues (2013) compared the U.S. sample to French-speaking young adults in Switzerland and France, as well as to an Italian sample. Data were collected from a total of 365 participants consisting of university students, university career counseling center clients, and public career counseling center clients. By using single group CFAs, the authors found the fourfactor model to fit well in all three samples. Configural and metric invariance were also largely supported; scalar invariance, however, was not. In the French-speaking sample, the Neuroticism/Negative Affect and the Lack of Readiness scales were found to be particularly 
problematic. In the Italian sample, three of the four scales were found to lack invariance, with Interpersonal Conflicts being the only exception.

A third international study did not find evidence for measurement invariance between a U.S. and South Korean sample (Abrams et al., 2014). In the South Korean sample, data were collected from 574 students in seven high schools, with a mean participant age of 16.96. Using exploratory factor analysis, the authors found a five-factor model of career indecision that was supported in a random subset of the original South Korean sample. This new five-factor model included the four factors found in all previous studies using the CIP-65 (Abrams et al., 2013, Carr et al., 2014, \& Hacker et al., 2013) with the addition of a factor which was labeled Need for Information. Also, unlike the previously mentioned studies in which all factors were significantly correlated, two pairs of factors were not (Choice/Commitment Anxiety with Lack of Readiness, and Need for Information with Interpersonal Conflicts). It is important to note that to date, the South Korean sample has been the only one not to consist either entirely or mostly of college students.

In sum, the CIP-65's factor invariance has largely been supported in the literature.

Internal consistency estimates have been shown to be high, and the scores from all four subscales correlate well with self-reported levels of undecidedness and thus give evidence for construct validity. However, there are several psychometric properties of the scores about which we still know little. For example, no study has examined the test-retest reliability of the CIP-65's subscale scores. Also of importance is its generalizability to non-college populations.

\section{Purpose of this Study and Hypotheses}

The first goal of this study was to replicate the CIP-65's four-factor structure of 1) Neuroticism/Negative Affect, 2) Choice/Commitment Anxiety, 3) Lack of Readiness, and 4) 
Interpersonal Conflicts in a sample of U.S. college students. Whereas the measurement invariance has been tested in three international studies (Abrams et al., 2013; Abrams et al., 2014; Carr et al., 2013), all were compared to the original sample of 488 U.S. college students collected by Hacker and colleagues (2013). Therefore, replication in a second sample, similar to the original, was deemed warranted.

Hypothesis 1: The factor structure of the college-student sample in the present study was expected to be invariant with the factor structure obtained in the original college-student sample.

The second goal of this study was to examine the measurement invariance between college students and young adults not enrolled in college. Generalizability is an important property in instruments if they are to be used in diverse populations. With the exception of one study which sampled Korean high school students (Abrams et al., 2014), every CIP-65 sample has comprised college students. Interestingly, the Korean sample is the only study in which the four-factor structure has not been replicated. It is true that college students make an ideal population among whom to assess career indecision given their age, general lack of experience and an almost unlimited number of career choices. If the CIP- 65 is to be used by counselors who are not limited to advising college students in a university setting, however, its factor structure should be generalizable to individuals who are not college students.

According to the U.S. Department of Labor (2014), only 65.9\% of high school graduates entered college in 2013. Once an ever-increasing trend, college enrollment peaked at $70.1 \%$ in 2009 before falling each of the last 4 years for which survey data are available. More than one third of high school graduates are not entering college, and still more students do not finish a degree. Sometimes termed the forgotten half, young adults who do not pursue college are an understudied population (Blustein et al., 2002). Nonetheless, many non-college youth are 
unemployed or trapped in unsatisfying jobs. It stands to reason that many current and future clients struggling with career indecision are likely to be in a fundamentally different position than the participants in the CIP-65 studies. For example, young adults who are not enrolled in college may have less access to career-relevant information, less time to make a decision, and fewer available career options than college students. These differences, among others, could impact how college students and their non-college counterparts see the construct of career indecision and result in measurement variance between these two groups.

Surprisingly, the literature comparing the characteristics between college students and their non-college peers is sparse. Lindholm (2006) notes this dearth of information regarding individual differences of college students and their non-college-going peers, adding that the extent of our knowledge is largely limited to demographic information. For example, we know that men, minorities, and individuals from low-SES families are less likely to pursue college. By conducting group interviews, Lindholm (2006) found that common reasons among recent highschool students for deciding to forgo college included non-academically oriented home environments, financial reasons, and family responsibilities. In addition, self-efficacy has been proposed as an important factor for predicting college attendance (Bandura, 1995) but has not been empirically tested.

In a classic commentary of psychology's dependence on undergraduates for research, Sears (1986) posited that although college students look much like the general adult population, important differences may exist. For example, college students tend to have more identity confusion, less crystallized attitudes, more feelings of insecurity, and more egocentric attitudes than the general adult population. Henry (2006), in an article redux of Sears (1986), noted that even when controlling for age, college students tend to have greater cognitive skills and more 
unstable peer relationships than their non-college counterparts. College students are also far more liberal and egalitarian than the adult population as a whole. He concludes that:

[T]his illustration shows how differences can emerge between a university sample and a general adult sample in theoretical ways, patterns that go beyond the developmental issues suggested by Sears (1986). At the very least, these data suggest that we cannot assume that student sample results will reflect patterns in a general adult population. (p. 59)

Concerning the workplace, Pascarella and Terenzini (2005) found that college can have a significant impact on students. They tend to become more knowledgeable, focused, and obtain a higher level of workplace readiness during their time at college. The authors also found that college tends to lower job satisfaction, possibly by way of raised expectations about the workplace.

In sum, many differences have been observed between college students and young adults who do not attend college. Whereas these differences might not influence many psychological studies, the construct of career indecision is inherently intertwined with college attendance given that a main goal of attending college is to enhance one's job prospects. Samples consisting entirely of undergraduates might therefore substantially impact factor analytic results. I posed this as an exploratory question rather than a directional hypothesis because theory and research on the differences between college and non-college populations do not provide enough consistent trends to lead me to make specific predictions. 
Research Question 1: To what extent do college and non-college populations show configural, metric, and scalar invariance?

Another psychometric property that has not been examined in the CIP-65 is test-retest reliability. In measures of career indecision, at least a moderate degree of stability between test and retest is expected (Hartman, Fuqua, \& Jenkins, 1986). Exactly how much reliability one should expect from one point in time to the next is debated. Career indecision is at least a somewhat stable construct; if the problem were fleeting and consistently addressed on its own, clients would not feel the need to seek assistance. Alternatively, we can expect individual's level of career indecision to improve or decline with new information or life events. For example, finding that the career one had in mind has a poor outlook according to the most recent survey reported in the news may significantly decrease one's level of career decidedness, whereas newfound support from an important other may help to confirm it. Because of these natural fluctuations, it has been suggested that career indecision is inherently unstable and therefore, modest test-retest reliabilities would accurately reflect this instability (Hartman, Utz, \& Farnum, 1979).

Osipow (1980) reported two-week test-retest reliabilities ranging from .82 to .90 , and a six-week test-retest reliability of .70 for the Career Decision Scale's scores. Two-week reliabilities as low as .61 have been found (Hartman et al., 1979). Test-retest reliabilities were found ranging from .50 to $.72(M=.63)$ in the initial study for the Career Decision Difficulty Questionnaire, again suggesting moderate stability (Gati et al., 1996). To date, test-retest reliability information has not been examined for the CIP-65 or the CIP-167, the longer measure from which it was derived. Based on reliability data from other measures of career indecision, I expected to find modest test-retest reliability scores for CIP-65 scores. A six-week re-test period 
was chosen for examining the CIP-65 scores' test-retest reliability because it provides enough time for new information or life events to arise which might affect participants' level of career indecision, while limiting the number of students who withdraw from the study.

Because of the inherent stability of trait neuroticism (Cobb-Clark \& Schurer, 2012), I expected to find high test-retest reliability for Neuroticism/Negative Affectivity scores obtained six weeks apart. On the other hand, career- relevant information is easily obtained in short amounts of time. Because several lack-of-information items load on the CIP-65's Choice/Commitment Anxiety factor, I expected to find relatively low test-retest reliability between Choice/Commitment Anxiety scores obtained six weeks apart. Obtaining test-retest reliabilities for CIP-65 scores and subscores was deemed to be important because it would allow counselors to compare pre- and post-intervention scores to fluctuations that can be expected naturally.

Hypothesis 2: Six-week test-retest reliability coefficients were expected to be moderately positive (e.g., .50-.70).

Hypothesis 2a: Reliability coefficients were expected to be the highest for Neuroticism/Negative Affect scores and lowest for Choice/Commitment Anxiety scores.

Last, I sought to examine the relation between choice/commitment anxiety and decisionmaking tendencies. First coined by Simon (1955), the term satisficers refers to individuals who tend to settle for an adequate option. In contrast, the term maximizers refers to individuals who seek the best possible option and do not stop searching until that option is found (Schwartz et al., 2002). Maximizing/satisficing is usually conceptualized as a unidimensional individual difference with extreme maximizers on one end and extreme satisficers on the other. 
Maximizers have been found to be less satisfied with their choices (Schwartz et al., 2002), explore more options, and feel more anxiety about those options (Diab, Gillespie, \& Highhouse, 2008). In relation to job-seeking, Iyengar, Wells, and Schwartz (2006) found that college senior maximizers apply for more jobs, experienced more job-related anxiety, and sought more career information than satisficers. Because of these patterns, Brown et al. (2012) suggested examining the relationship between maximization tendencies and career indecision using the CIP-167. Individuals who seek the best possible job (i.e., maximizers) should have trouble committing if they do not know other available options, which reflects a CIP-65 item that has been found to load saliently on the Choice/Commitment Anxiety scale. In fact, given the relatedness of the Choice/Commitment Anxiety scale and the construct of maximization, I expected that scores on the two measures would overlap considerably.

Hypothesis 3: Maximizing tendency was expected to be positively associated with scores on the CIP-65 Choice/Commitment Anxiety subscale. In addition, maximizing/ satisficing scores were expected to account for a large portion of the variance $\left(r^{2}=0.2-0.4\right)$ in Choice/Commitment Anxiety scores.

Examining this overlap was expected to yield useful information because it would provide additional clarity on the underlying sources of career indecision and better enable practitioners to counsel individuals with career choice-making difficulties. I expected maximizing tendencies to be correlated with overall career indecision scores primarily by way of the Choice/Commitment Anxiety subscale; I did not expect a significant correlation between maximizing tendencies and any of the other three factors. Finding that maximizing tendencies correlate highly with Choice/Commitment Anxiety scores, but none of the other three factors, would provide evidence for the Choice/Commitment Anxiety scores' discriminant validity. 


\section{CHAPTER III: METHOD}

\section{Participants and Procedure}

Data were collected from two samples: (a) undergraduate college students at a large Midwestern university and (b) Amazon Mechanical Turk (MTurk) workers. MTurk is an online crowdsourcing marketplace that allows individuals and businesses to set a small monetary payment in exchange for tasks or surveys that require human response. Although MTurk workers are rewarded monetarily for their participation, the amount is typically very small. Participants have been found to be internally motivated (e.g., for enjoyment) rather than externally motivated (Buhrmester, Kwang, \& Gosling, 2011; Paolacci \& Chandler, 2014). Similarly, it has also been found that data quality is not affected by compensation amount (Buhrmester et al., 2011). In sum, the potentially confounding factor of compensation seems not to be an issue. MTurk workers consist of individuals from over 190 countries, but workers from the United States and India are the vast majority (Ross et al., 2010). For the present study, only participants from the United States were allowed to complete the survey to avoid the potentially confounding factor of country of residence. Data were collected from the college students and the MTurk workers simultaneously to minimize the risk that time of year would be a confound.

Although the general guideline for structural equation models is 5-10 participants for each estimated parameter (Kline, 2010; approximately 1400 for each group in this case), 500 college participants and 500 non-college participants were sought for this study. Hacker et al. (2013) found via a post-hoc power analysis that a sample size of $N=488$ was adequate to confirm the factor structure of the CIP-65. Final sample sizes in the current study $(N=529$ university participants and $N=472$ MTurk participants) closely approximated these a priori values. 


\section{University Sample}

The students at the Midwestern university who were recruited via their psychology department's research-participation system followed a hypertext link to an online survey containing the study's measures. In exchange for completing the survey, participants were awarded extra credit in a psychology class. If the student decided to participate, he or she was instructed to click a link that led to the survey. The survey required students to enter their university log-in identifications (which was used for the follow-up study invitation and to limit each person's participation to a single instance). The first page of the survey was a consent screen, the terms of which needed to be accepted before the participants could access the survey. Upon accepting the conditions, participants first completed the demographic questions followed by the CIP- 65 and maximizing tendency measures, which were administered in a counterbalanced order based on birth month (odd vs. even). After completion of the measures, a debriefing screen described the purposes of the study. Six weeks after the original survey completion, a portion of the students was asked via email to complete the survey a second time, also in exchange for course credit.

Data were initially collected from 546 participants, but after removing cases with $5 \%(k=$ 4) or more missing CIP-65 items, the final sample became $n=529$. A small percentage (3.4\%) of participants failed to pass one or both screening questions used to gauge attention. Because including these participants did not lead to any significant differences when running analyses, they were not excluded from the final sample. Participants ranged in age from 18 to 28 years ( $M$ $=19.19, S D=1.45)$. The majority were women $(81.3 \%)$ and Caucasian $(81.3 \%)$. Other ethnicities included Black (7.8\%), Mexican American (5.1\%), Multiracial (2.1\%), Hispanic (1.5\%), Asian American (1.3\%), and American Indian (.2\%). Participants' average career 
decidedness $(M=4.92, S D=1.28)$ was between "Slightly Decided" (4) and "Moderately Decided" (5) on a six-point Likert scale. By credits, $45.0 \%$ were Freshman, $23.1 \%$ were Sophmores, $20.2 \%$ were Juniors, $10.2 \%$ were Seniors, and $1.3 \%$ were in their fifth year or higher (but not graduate students).

The Time-2 sample $(n=107)$ ranged in age from 18 to $27(M=19.55, S D=1.60)$. Again, the majority were women $(87.9 \%)$ and Caucasian $(89.7 \%)$. Their average career decidedness $(M$ $=5.04, S D=1.24$ ) was between "Moderately Decided" (5) and "Completely Decided" (6) on a six-point Likert scale. The Time-2 sample consisted of slightly more women, $\chi^{2}(1, N=525)=$ $4.44, p=.04$, were more likely to be Caucasian (non-Caucasian ethnicities were collapsed into one category), $\chi^{2}(1, N=525)=6.41, p=.01$, and were further along in school, $\chi^{2}(1, N=528)=$ $13.81, p=.01$, than the participants who only took the survey once. However, there was no difference in average career decidedness, $(M=4.88, S D=1.31$ and $M=5.04, S D=1.24$ in the Time-1-only and Time-2 samples, respectively), $t(528)=1.13, p=.26$, between participants for whom Time 2 data were and were not obtained.

When comparing average CIP-65 factor and MTS scores, the Time 1-only sample scored higher on LR $(p=.02)$ and IC $(p=.03)$, the Time- 2 sample scored higher on the MTS $(p=.04)$, and there were no differences in NNA $(p=.56)$ or CC $(p=.24)$ scores. However, effect sizes were small (all $d$ 's $<.27$ ).

\section{MTurk Sample}

The MTurk participants were able to find the survey on Amazon's Mechanical Turk website and choose whether to participate in exchange for $\$ 0.20$ in compensation. Data were initially collected from 1071 participants, but after discovering that some workers $(n=111)$ had taken the survey more than once, they were removed, leaving $n=960$. After removing cases with 
$5 \%(k=4)$ or more missing CIP-65 items, the sample became $n=865$. To keep the MTurk and college samples as similar as possible, MTurk participants over the age of $30(n=97)$ were removed. Additionally, to keep the distinction between the college and non-college samples as clean as possible, participants who were currently attending college at least half-time $(n=200)$ or who already had a Bachelor's degree or higher $(n=96)$ were not included in this study. I chose simply to remove these participants instead of combining them with the university sample to keep the samples and sample sizes as similar as possible to each other. This process left a total MTurk sample of $n=472$. A small percentage (6.4\%) of participants failed to pass one or both screening questions used to gauge attention. Because including these participants did not lead to any significant differences when running analyses, they were not excluded from the final sample. Participants ranged in age from 18 to $30(M=25.58, S D=3.18)$. There were slightly more women $(56.5 \%)$ than men $(42.4 \%)$, and the majority were Caucasian $(72.2 \%)$. Other ethnicities included Black (9.3\%), Asian American (4.9\%), Mexican American (4.2\%), Hispanic (3.6\%), Multiracial (2.8\%), and American Indian (1.3\%). Participants' average career decidedness $(M=$ $3.44, S D=1.60$ ) was between "Slightly Undecided" (3) and "Slightly Decided" (4) on a sixpoint Likert scale. Because it is more difficult to contact MTurk participants, they were not assessed for test-retest reliability purposes.

\section{Comparison of University and MTurk Samples’ Demographics}

The university sample $(M=19.19 ; S D=1.45)$ was younger on average than the MTurk sample $(M=25.58 ; \mathrm{SD}=3.18), t(616.93)=37.94, p<.001, d=2.59$, consisted of significantly more women, $\chi^{2}(1, N=990)=74.90, p<.001$, were more career decided $(M=4.92$ and 3.44 in the university and MTurk samples, respectively), $t(895.59)=16.03, p<.001, d=1.02$, and were higher in terms of mothers' median education (Associate's degree and high school diploma in the 
university and MTurk samples, respectively; $\chi^{2}(1, N=995)=81.95, p<.001$; college degree and non-college degree categories were each collapsed), and fathers' education (Associate's degree and high school diploma in the university and MTurk samples, respectively; $\chi^{2}(1, N=996)=$ $60.51, p<.001$; college degree and non-college degree categories were each collapsed) than the MTurk sample. Thus, the college and non-college participants clearly differed from each other in important ways, but it is likely that this is reflective of the demographics of those populations themselves and is not necessarily a sampling issue.

\section{Measures}

\section{Demographic Items}

Participants were asked to report their gender, age, race/ethnicity, classification of college student or non-college student (based on definitions provided above), year in school (if applicable), and major (if applicable).

\section{Career Indecision}

The Career Indecision Profile-65 (CIP-65; Hacker, Carr, Abrams, \& Brown, 2013) assessed participants' level of career indecision. The CIP-65 consists of 65 items. Respondents indicate their degree of agreement on a 1 (strongly disagree) to 6 (strongly agree) scale. The CIP-65 measures career indecision with four subscales: Neuroticism/Negative Affinity, Choice/Commitment Anxiety, Lack of Readiness, and Interpersonal Conflicts. The Neuroticism/ Negative Affectivity subscale is characterized by questions inquiring about the tendency to experience negative emotions, especially sadness, anxiety, and insecurity (e.g., "I often feel fearful and anxious."). The Choice/Commitment Anxiety subscale is characterized by questions inquiring about the difficulty of making choices in general or about careers in particular (e.g., "I am not sure I can commit to a specific career because I don't know what other options might be 
available.”). The Lack of Readiness subscale is characterized by questions pertaining to selfefficacy and goal-oriented behavior (e.g., "I am quite confident that I will be able to overcome obstacles to getting the career I want."). The Interpersonal Conflicts subscale is characterized by questions pertaining to discrepancies between personal career goals and the plans of important others (e.g., "Important people in my life disagree about the career I should choose."). Cronbach's alpha for the scores from all four subscales were found to be high in both the university sample (Neuroticism/Negative Affect: $\alpha=.94$, Choice/Commitment Anxiety $\alpha=.96$, Lack of Readiness $\alpha=.88$, Interpersonal Conflicts $\alpha=.86$ ) and the MTurk sample (Neuroticism/Negative Affect: $\alpha=.95$, Choice/Commitment Anxiety $\alpha=.95$, Lack of Readiness $\alpha=.92$, Interpersonal Conflicts $\alpha=.87$ ). These reliability estimates are very similar to those found by Hacker and colleagues (2013; Neuroticism/ Negative Affect $\alpha=.93$, Choice/Commitment Anxiety $\alpha=.97$, Lack of Readiness $\alpha=.88$, Interpersonal Conflicts $\alpha=$ $.89)$.

The CIP-65 includes an item assessing overall career decidedness. Participants were asked to explicitly rate their level of career decidedness on a six-point scale ranging from "Completely Undecided" to "Very Decided". This item is useful to provide evidence of construct validity.

\section{Maximizing vs. Satisficing}

The Maximizing Tendency Scale (Diab et al., 2008) was used to measure participants' degree of maximizing versus satisficing. The Maximizing Tendency Scale consists of 9 items (e.g., "I don't like having to settle for 'good enough."). Respondents indicate their degree of agreement on a 1 (strongly disagree) to 7 (strongly agree) scale. Cronbach's alpha of $\alpha=.83$ and $\alpha=.86$ were found, for the university and MTurk samples, respectively. Again, both values are 
similar to that found by Diab and colleagues $(2008 ; \alpha=.80)$ as well as Giacopelli, Simpson, Dalal, Randolph, \& Holland (2013; $\alpha=.84)$.

\section{Screening Questions}

In accordance with recommendations by Goodman, Cryder, and Cheema (2013), two screening questions were used to gauge attention and English-language comprehension.

\section{Data Analyses}

Single-group CFAs using LISREL 8.80 (Joreskog \& Sorbom, 2006) were conducted on both the university and MTurk samples independently to assess model fit. Multi-group CFAs using LISREL 8.80 were then conducted to compare the factor structure of the CIP-65 across the university ( $n=529)$ and original college student ( $n=488$; Hacker et al., 2013) samples, as well as across the university $(n=529)$ and MTurk $(n=472)$ samples. Maximum likelihood estimation using covariance matrices was used in all models. To be consistent with previous CFAs of the CIP-65 (e.g., Hacker et al., 2013), missing data was imputed for cases with $k=3$ or fewer missing CIP-65 items. Cases with $k=4$ or more missing CIP-65 items were excluded from all single-group and multi-group CFAs.

\section{Assessing Model Fit}

Goodness of fit was evaluated using four separate fit statistics, including two absolute fit indices: the root mean square error of approximation (RMSEA) and the standardized root mean square residual (SRMR), and two relative fit indices: the non-normed fit index (NNFI) and the comparative fit index (CFI). For both absolute fit indices, smaller values indicate better model fit. For the RMSEA, MacCallum, Browne, and Sugawara (1996) suggested 0.01, 0.05, and 0.08 to indicate excellent, good, and mediocre fit, respectively, while Hu and Bentler (1999) suggest a .06 cutoff criterion. Hu and Bentler (1999) also suggest that values of .08 or less indicate 
adequate model fit when using the SRMR. For both relative fit indices, larger values indicate better model fit with 1.00 indicating a perfectly fitting model. Hu and Bentler (1999) suggest that NNFI and CFI values above .95 represent good fit.

\section{Assessing Measurement Invariance}

Configural invariance was evaluated first through single-group CFAs in which each sample was separately evaluated for goodness of fit. Upon finding evidence for configural invariance, the results were combined and used as a baseline for the more restrictive models and used to assess metric and scalar invariance. Measurement invariance was assessed through two different criteria. Nested models were first compared using the chi-square difference test. In addition, changes in CFI values were also examined due to sample-size sensitivity of the chisquare statistic. I followed the recommendation of Meade, Johnson, and Brady (2008) by interpreting a difference in CFI values of greater than .002 between nested models as evidence of measurement variance. 


\section{CHAPTER IV: RESULTS}

\section{Correlations, Descriptive Statistics, and Internal Consistency}

Means, standard deviations, Cronbach's alphas, and correlations for the four factor scores of the CIP-65, maximizing tendency scores, and overall career decidedness scores for both the university and MTurk samples are shown in Table 1. All four CIP-65 factor scores were significantly positively correlated with each other in both samples. However, scores on the Neuroticism/Negative Affectivity scale correlated more strongly with scores on the Choice/Commitment Anxiety $(z=3.15, p=.002)$, Lack of Readiness $(z=2.78, p=.005)$, and Interpersonal Conflicts $(z=1.97, p=.049)$, scales in the MTurk sample than in the university sample. Maximizing tendency was, surprisingly, significantly negatively correlated with scores on all four factors in the MTurk sample, as well as with scores on one factor (Lack of Readiness) in the university sample. That is, maximizers, were, on average, were more career-decided than satisficers. Consistent with this finding, maximization was positively correlated with the oneitem measure of career decidedness. The one-item measure of career decidedness was, as expected, significantly negatively correlated with all four factors in the MTurk sample, and with three of the four factors (minus Neuroticism/Negative Affectivity) in the university sample. That is, on average, participants who rated themselves as more decided about their career direction scored lower on the CIP-65, which measures career indecision.

Participants in the university sample had higher average scores on the Neuroticism/ Negative Affectivity factor $(t(960.94)=2.23, p=.026, d=.14)$ and overall career decidedness $(t(895.59)=16.03, p<.001, d=1.02)$, and were more likely to be maximizers $(t(934.42)=7.27$, $p<.001, d=.46)$ than the MTurk participants. However, participants in the MTurk sample had 
higher average scores on the Choice/Commitment Anxiety factor $(t(997.36)=7.25, p=.003, d=$ $.45)$, the Lack of Readiness factor $(t(896.74)=9.22, p<.001, d=.58)$, and the Interpersonal Conflicts factor $(t(946.09)=9.91, p<.001, d=.63)$ than the university participants.

Table 1.

Means, Standard Deviations, Cronbach's Alphas, and Correlations among CIP-65 Factor and MTS Scores for University and MTurk Samples

\begin{tabular}{|c|c|c|c|c|c|c|}
\hline Measure & 1 & 2 & 3 & 4 & 5 & 6 \\
\hline 1. Neuroticism/Negative Affectivity & 1 & $.57 * *$ & $.38 * *$ & $.40 * *$ & $-.16^{*}$ & $-.34 * *$ \\
\hline 2. Choice/Commitment Anxiety & $.42 * *$ & 1 & $.28 * *$ & $.43^{* *}$ & $-.11 *$ & $-.56 * *$ \\
\hline 3. Lack of Readiness & $.22 * *$ & $.26 * *$ & 1 & $.27 * *$ & $-.68 * *$ & $-.33 * *$ \\
\hline 4. Interpersonal Conflicts & $.29 * *$ & $.37 * *$ & $.26 * *$ & 1 & $-.10 *$ & $-.24 * *$ \\
\hline 5. Maximizing Tendency & .00 & -.06 & $-.62 * *$ & -.08 & 1 & $.16^{* *}$ \\
\hline 6. Career Decidedness & $.13 * *$ & $-.61 * *$ & $-.30 * *$ & $-.17 * *$ & $.15^{* *}$ & 1 \\
\hline$M$ (MTurk sample) & 3.49 & 3.56 & 2.53 & 2.72 & 4.95 & 3.44 \\
\hline SD (MTurk) & 1.10 & 1.06 & 0.82 & 1.27 & 1.03 & 1.60 \\
\hline Cronbach's $\alpha$ (MTurk) & .95 & .95 & .92 & .87 & .86 & NA \\
\hline$M$ (University sample) & 3.64 & 3.06 & 2.10 & 1.97 & 5.39 & 4.92 \\
\hline$S D$ (University) & 1.01 & 1.15 & 0.65 & 1.12 & 0.89 & 1.28 \\
\hline Cronbach's $\alpha$ (University) & .94 & .96 & .88 & .86 & .83 & NA \\
\hline
\end{tabular}

Note. $* \mathrm{p}<.05 ; * * \mathrm{p}<.01$. Data from the MTurk sample $(N=472)$ are above the main diagonal, and data from the university sample $(N=529)$ are below the main diagonal. 


\section{Replication in a University Sample}

A single-group CFA was performed on the university sample $(N=529)$ first to confirm that the factor structure of the university sample collected in the present study closely matched the four-factor structure found by Hacker and colleagues $(2013 ; N=488)$. It was revealed that the hypothesized four-factor model fit the data well, and all reported fit indices closely matched those found by Hacker and colleagues (2013; see Table 2). Both the NNFI and CFI exceeded the .95 recommendation. The RMSEA fell below the .08 recommendation, while the SRMR was only slightly higher than .08 . Thus, configural invariance was established for the four-factor model across both college student samples and Hypothesis 1 was supported. After confirming the four-factor structure in the sample comprising college students, I turned next to assessing the measurement invariance between college students and non-college students.

Table 2.

Measures of Fit.

\begin{tabular}{lcccccc}
\hline & $X^{2}$ & $d f$ & NNFI & CFI & SRMR & RMSEA \\
\hline Hacker et al. (college; $N=488)$ & 6495.63 & 2009 & .95 & .95 & .078 & .074 \\
University (college; $N=529)$ & 6360.25 & 2009 & .96 & .96 & .082 & .071 \\
MTurk (non-college; $N=472)$ & 6415.11 & 2009 & .96 & .96 & .086 & .078 \\
\hline
\end{tabular}

Note . NNFI $=$ non-normed fit index, $\mathrm{CFI}=$ comparative fit index, SRMR $=$ standardized root mean square residual, RMSEA = root mean square error of approximation.

\section{Measurement Invariance: College Student and Non-College Samples}

A single-group CFA was performed on the MTurk sample $(N=472)$ to establish configural invariance across college and non-college students. Configural invariance must be 
established before stricter forms of measurement invariance such as metric and scalar invariance can be tested. The four-factor model fit the data well, and fit indices nearly mirrored those of the university sample (see Table 2). Again, the NNFI, CFI, and RMSEA met criteria, whereas the SRMR only narrowly missed the recommended value of .08. Thus, configural invariance was established for the four-factor model across college student and non-college samples. For a full list of factor loadings in both groups, see Table 3.

I moved next to multi-group CFA modeling to assess metric invariance. For these analyses, a baseline model (the combined university and MTurk samples with no cross-group equality constraints) was compared to models in which various factor loadings were constrained to be equal across groups. First, to conduct an omnibus test of metric invariance, all factor loadings were constrained to be equal and compared to the baseline model. As can be seen in Table 4, a chi-square difference test revealed that the baseline model fit the data significantly better $(p<.001)$ than the model in which all factor loadings were constrained to be equal. The change in $\mathrm{CFI}$ values $(\Delta \mathrm{CFI}=.017)$ adds further evidence to the lack of metric invariance between samples.

After finding a lack of omnibus metric invariance across the college student and noncollege samples, I conducted further tests of metric invariance factor by factor to see which factors yielded the largest discrepancies of fit. In these four tests, loadings on one factor were constrained to be equal, while loadings were free to vary on the three remaining factors. I chose to conduct tests of metric invariance by factor instead of individual item due to the large number of items that compose the CIP-65. When compared with the baseline model, chi-square difference tests were significant for both the model in which Choice/Commitment Anxiety items were constrained to be equal $(p<.001)$ and the model in which Lack of Readiness items were 
constrained to be equal $(p<.001)$. The changes in CFI values $(\Delta \mathrm{CFI}=.007$ and $\Delta \mathrm{CFI}=.006$, respectively) corroborate these results, as changes greater than .002 indicate a lack of metric invariance. However, metric invariance was found between the unconstrained baseline model and the remaining two models: the model in which Neuroticism/Negative Affectivity items were constrained to be equal $(p=.110)$ and the model in which Interpersonal Conflicts items were constrained to be equal $(p=.188)$. Again, the changes in CFI values $(\Delta \mathrm{CFI}=.002$ and $\Delta \mathrm{CFI}<$ .001 , respectively) validate these tests. Despite the metric invariance found for these two factors, I chose to not pursue tests of scalar invariance given the lack of metric invariance in the omnibus comparison.

In sum, because the same four factors emerged in the college student and non-college samples, the CIP-65 can be considered configurally invariant. However, metric invariance, which is concerned with the interpretation of test items across groups, was not found. Whereas it is true that full metric variance is rare, and it is acceptable if a small percentage of items show a lack of metric invariance, items in two of the four factors showed metric invariance, which was enough evidence to conclude that several test items are interpreted differently across groups. 
Table 3.

Within-Group Completely Standardized Loadings for the CIP-65 across Samples.

\begin{tabular}{|c|c|c|}
\hline Item (Factor) & $\begin{array}{c}\text { University factor } \\
\text { loading }\end{array}$ & $\begin{array}{l}\text { MTurk factor } \\
\text { loading }\end{array}$ \\
\hline Takes a long time to feel good after setbacks (NNA) & .59 & .72 \\
\hline Often feel like crying (NNA) & .68 & 67 \\
\hline Often feel tired and worn out (NNA) & .59 & .65 \\
\hline Often feel overwhelmed (NNA) & .67 & .72 \\
\hline Easily embarrassed (NNA) & .67 & .69 \\
\hline Take setbacks harder than others (NNA) & 69 & .75 \\
\hline Hard to make decisions without help (NNA) & .59 & .67 \\
\hline Worry what others think of me (NNA) & .59 & .65 \\
\hline Hard time forgetting when things go wrong (NNA) & .66 & .77 \\
\hline Hope my problems will just go away (NNA) & .59 & .60 \\
\hline Often so sad it's hard to go on (NNA) & .69 & .70 \\
\hline I'm a worrier (NNA) & .64 & .72 \\
\hline Focus on what will go wrong in deciding (NNA) & .66 & .71 \\
\hline Often feel fearful and anxious (NNA) & .79 & .84 \\
\hline Think about alternatives after deciding (NNA) & .56 & .58 \\
\hline Sleeping more or less (NNA) & .53 & .49 \\
\hline Often feel insecure (NNA) & .80 & .82 \\
\hline Stress makes me ill (NNA) & .75 & .75 \\
\hline Often feel ashamed (NNA) & .77 & .79 \\
\hline Need encouragement from others when deciding (NNA) & .58 & .57 \\
\hline No confidence in decisions unless friends support them (NNA) & .65 & .66 \\
\hline Uncomfortable committing to specific career direction (CCA) & .52 & .49 \\
\hline Need to learn more about what I want (CCA) & .68 & .64 \\
\hline Interests might change too much (CCA) & .77 & .73 \\
\hline Often feel discouraged about deciding (CCA) & .76 & .77 \\
\hline Sometimes feel directionless (CCA) & .53 & .64 \\
\hline Can't decide between two good options (CCA) & .76 & .70 \\
\hline Need a better idea of my talents (CCA) & .69 & .71 \\
\hline Conflicted because I find a number of career appealing (CCA) & .76 & .66 \\
\hline Need to learn more about myself (CCA) & \multicolumn{2}{|c|}{ (Table Continues) } \\
\hline
\end{tabular}




\begin{tabular}{|c|c|c|}
\hline Item (Factor) & $\begin{array}{l}\text { University factor } \\
\text { loading }\end{array}$ & $\begin{array}{l}\text { MTurk factor } \\
\text { loading }\end{array}$ \\
\hline Difficult because I like so many things (CCA) & .76 & .70 \\
\hline Rather keep myself open than committing (CCA) & .68 & .46 \\
\hline Not enough occupational information (CCA) & .87 & .76 \\
\hline Know options but not ready to commit (CCA) & .73 & .50 \\
\hline Need to learn more about my interests (CCA) & .82 & .78 \\
\hline Concerned interests might change (CCA) & .75 & .77 \\
\hline Can’t commit, don't know other options (CCA) & .85 & .80 \\
\hline Concerned goals might change (CCA) & .79 & .80 \\
\hline Need more information on successful options (CCA) & .81 & .79 \\
\hline Don't know enough about occupations (CCA) & .84 & .80 \\
\hline Need to learn decision-making (CCA) & .77 & .78 \\
\hline Need information on careers might like (CCA) & .84 & .81 \\
\hline Feel nervous when thinking about deciding (CCA) & .82 & .79 \\
\hline Hard time narrowing down (CCA) & .88 & .85 \\
\hline Don't know much about occupations (CCA) & .68 & .64 \\
\hline Strive hard to achieve goals (LR) & .64 & .65 \\
\hline Plan ahead for important decisions (LR) & .55 & .58 \\
\hline Always think carefully before deciding (LR) & .51 & 52 \\
\hline Thoroughly consider consequences (LR) & .40 & .48 \\
\hline Keep going when bad things happen (LR) & .45 & .61 \\
\hline Usually able to carry out my plans (LR) & .59 & .69 \\
\hline I'm a worthwhile person (LR) & .62 & .72 \\
\hline Confident I'll achieve career goals (LR) & .68 & .74 \\
\hline Given effort, I can solve most problems (LR) & .67 & .72 \\
\hline Confident I can overcome obstacles (LR) & .59 & .70 \\
\hline Try to excel at everything (LR) & .58 & .68 \\
\hline Will be able to find a career (LR) & .66 & .68 \\
\hline Always work productively (LR) & .71 & .66 \\
\hline Confident find career perform well in (LR) & .66 & .71 \\
\hline Verify information when deciding (LR) & .38 & .46 \\
\hline Going against wishes of others (IC) & .66 & .68 \\
\hline Contradictory information from others (IC) & .60 & .64 \\
\hline Important people don't support plans (IC) & .81 & .81 \\
\hline Important people disagree with plans (IC) & .91 & .84 \\
\hline Important people discourage plans (IC) & .85 & .81 \\
\hline
\end{tabular}


Table 4.

Results of Metric Invariance Tests between University $(N=529)$ and MTurk (N=472) Samples

\begin{tabular}{lccccccc}
\hline & $X^{2}$ & $\Delta X^{2}$ & $\mathrm{df}$ & $\Delta \mathrm{df}$ & p-value & $C F I$ & $\Delta C F I$ \\
\hline Baseline model (no constraints) & 7112.14 & & 4018 & & & .232 & \\
All loadings invariant & 7245.06 & 132.92 & 4083 & 65 & $<.001$ & .215 & .017 \\
NNA loadings invariant & 7141.25 & 29.11 & 4039 & 21 & .110 & .230 & .002 \\
CC loadings invariant & 7165.82 & 53.68 & 4042 & 24 & $<.001$ & .225 & .007 \\
LR loadings invariant & 7153.49 & 41.35 & 4033 & 15 & $<.001$ & .226 & .006 \\
IC loadings invariant & 7119.61 & 7.47 & 4023 & 5 & .188 & .232 & $<.001$
\end{tabular}

Note. NNA = neuroticism/negative affectivity, $\mathrm{CCA}=$ choice/commitment anxiety, $\mathrm{LR}=$ lack of readiness, $\mathrm{IC}=$ interpersonal conflicts, $\mathrm{CFI}=$ comparative fit index. All contrasts are with the baseline model.

\section{Test-Retest Reliability}

To examine the CIP-65 scores' test-retest reliability, scores from the 107 college-student participants who took the CIP-65 twice were examined. Test-retest correlations for scores from all four CIP-65 factors were high. Choice/Commitment Anxiety scores had the highest test-retest reliability $(r=.85)$, followed by Neuroticism/Negative Affectivity $(r=.79)$, Lack of Readiness $(r=.78)$, and Interpersonal Conflicts $(r=.58)$. The one-item measure of career decidedness had a test-retest reliability coefficient of $r=.66$. Hypothesis 2 was supported in that six-week reliabilities were in the predicted range or higher for all four factors of the CIP-65, which mirrors other measures of career indecision. However, Hypothesis 2a was not supported. Reliability was very high for Neuroticism/Negative Affectivity scores $(r=.79)$, as predicted due to the stable nature of neuroticism, but reliability for Choice/Commitment Anxiety scores, which were predicted to be the lowest, were even higher $(r=.85)$. 


\section{Relation with Maximization}

As reported in Table 1, the tendency to maximize was not found to be positively correlated with Choice/Commitment Anxiety scores. In fact, the scores from these measures were slightly negatively correlated $(r=-.11)$ in the MTurk sample, and although not significant, also had a negative relation $(r=-.06)$ in the university sample. Even more surprising, given that it was not hypothesized, was the large negative correlation between maximizing tendency and Lack of Readiness scores in both the MTurk $(r=-.68)$ and university $(r=-.62)$ samples. 


\section{CHAPTER V: DISCUSSION}

The purpose of this study was to conduct a more thorough evaluation of the psychometric properties of the CIP-65, a relatively new measure of career indecision that is the product of meta-analytic work (Brown \& Rector, 2008). To accomplish this purpose, I conducted

confirmatory factor analyses both to replicate the factor structure in a college student sample and to examine the factor structure in a non-college sample. I also provided evidence for strong testretest reliability and examined the relationship of career indecision with another construct: maximization. This research is important because, if the CIP-65 is to be used widely in practice, researchers and practitioners alike should know as much as possible about the measure, especially when being used in diverse populations.

\section{Significance of Measurement Invariance Results}

The configural invariance found across two college student samples is an important step in the vetting process of the CIP-65. Not only was the factor structure replicated across two samples, but across years (2013 vs. 2015) and collection method (pencil-and-paper in the Hacker et al. research vs. this study's online survey) as well. In addition, this replication provides further validity for the international measurement invariance studies (Abrams et al., 2013; Carr et al., 2013; Abrams et al., 2014) that have been conducted using a single U.S. sample.

Configural invariance was also found across the college student and non-college samples of the present study. This finding implies that vocational counselors who use the CIP-65 can assume that at the very least, the same four factors comprise the construct of career indecision for non-college clients as have been shown for college-students. However, the results of this study suggest that the CIP-65 does not have metric invariance across college-student and non- 
college samples. Specifically, it appears that this lack of metric invariance is due to several items on both the Choice/Commitment Anxiety and the Lack of Readiness scale.

In general, items on the Choice/Commitment Anxiety scale showed higher loadings for college students than for their non-college-going peers. This difference appears to be especially true for items that reflect a lack of commitment despite knowing the options and having enough information. Thus, it appears that this scale is defined more by a general lack of commitment for college students, whereas for non-college students, this scale may reflect more of a feeling of directionlessness due to not knowing oneself and one's interests, something that a college experience may assuage by letting students choose their major and elective credits. On the other hand, items on the Lack of Readiness scale showed higher loadings in the non-college sample than for college students. Particularly, items reflecting a lack of self-confidence and ability to overcome obstacles (items on this factor were reverse-coded) loaded higher in the MTurk sample than the university sample. This finding could mean that for non-college students, this factor, named Lack of Readiness, may be largely defined by a lack of self-worth, which could perhaps stem from a difference in self-efficacy that has been hypothesized between college students and their non-college-going peers (Bandura, 1995). Although the hypothesized four-factor model fit the non-college data well, it is possible that a different factor structure could fit non-college data better. Future research could use exploratory factor analysis to explore a restructuring, especially concerning the Lack of Readiness factor.

The only other study that has been conducted with non-college students (high school students were used instead; Abrams et al., 2014) also revealed some important differences in the factor structure of the CIP-65. Namely, a fifth factor labeled Need for Information emerged, and no correlation was found between Choice/Commitment Anxiety scores and Lack of Readiness 
scores. Of course, the participants in Abrams and colleagues' study differed in two important ways from the non-college participants in the present study, 1) they were from a different culture (South Korea) and 2) they had not forgone college, they had simply not had a chance to choose whether or not to attend college yet. Clearly, more research should be conducted to validate these findings and understand why these differences exist.

\section{Additional Psychometric Information about CIP-65 Scores}

In addition to measurement invariance, this study also provided information on two other psychometric properties: test-retest reliability and validity by way of examining the CIP-65's subscale scores relationships with maximization. Six-week test-retest reliability for the CIP-65 was hypothesized to be moderately high, in line with other measures of career indecision. Indeed, reliability coefficients for the four factors ranged from $r=.58$ to .85 . Interestingly, reliability coefficients between Choice/Commitment Anxiety scores were not the lowest of the four factors as hypothesized but the highest. This scale was predicted to have comparatively low test-retest reliability coefficients due to a number of lack-of-information items that load on this factor, coupled with the ease of which new information can be obtained. A possible explanation for this finding could be that, although several lack-of-information items load on this factor, many other items revolve around trait-like commitment issues such as being concerned that one's goals or interests might change.

Perhaps the most surprising finding of the present study was the relation between maximization scores and the scores of the individual scales of the CIP-65. It was hypothesized that maximizers would score higher on the Choice/Commitment Anxiety scale than satisficers. In fact, the correlation was not significant in the university sample, and was significantly negative in the MTurk sample. Even more surprising was the large negative correlation between 
maximizing tendency and Lack of Readiness scores in both samples. That is, those with greater satisficing tendencies were more likely to express a lack of readiness than were those with maximizing tendencies. This finding was validated by the positive relation found between maximizing tendency and the one-item measure of career decidedness that the CIP-65 includes. Maximizers were more likely to rate themselves as career-decided than satisficers.

While at first counterintuitive, this result makes some sense upon close inspection of the items that make up the MTS and the Lack of Readiness scale of the CIP-65. For example, two items on the Lack of Readiness scale read "I try to excel at everything I do" and "I thoroughly consider the consequences of a decision before I make it". It is not surprising that items like these correlate strongly with maximizing tendencies (e.g., not settling for second best, having high standards, etc.). It seems as if both measures are tapping the same construct: somewhere between a distinct planfulness and having a high achievement-orientation. Perhaps the factor currently labeled "Lack of Readiness" might actually be measuring a lack of the need to achieve and low drive, which would also explain why several self-worth items (e.g., "I think I am a worthwhile person") also load onto this factor. At any rate, the prediction by Brown et al. (2012) that Choice/Commitment Anxiety would relate to maximizing tendency was not supported in this study.

Due to the close relation between Lack of Readiness scores and maximizing tendencies in both samples, it seems that a more accurate name for the factor currently labeled "Lack of Readiness" might exist. Nearly all fifteen items in this scale concern careful planning, aiming to excel in one's endeavors, and confidence in oneself and one's career aspirations. As such, I recommend that this factor be renamed "Lack of Diligence" or "Lack of Conscientiousness". Not 
only does this label help to explain the factor's relation with maximizing tendencies, as outlined above, it also gives a less ambiguous description to the items that it consists of.

\section{Implications for Practice}

First, the results from this study generally support the use of the CIP-65 in research and practice in college student populations. The data also suggest that this measure is useful for noncollege populations, in that the overall factor structure appears to be consistent across

populations. However, practitioners should take into consideration the probable difference in the interpretation, especially in the Lack of Readiness factor. Also, it may be wise to use non-college norms when interpreting the scores.

Second, the test-retest coefficients provided by this study will help inform practitioners as to which factors are most likely to remain stable in the absence of intervention and which are the most likely to fluctuate. Specifically, Interpersonal Conflicts scores had only an $r=.58$ six-week test-retest coefficient, while the other three factor scores' coefficients exceeded $r=.77$. If practitioners use the CIP-65 to monitor treatment progress, these test-retest correlations would be useful baseline data. If an intervention is to be considered effective, a client's pre- and postintervention scores on the CIP-65 subscales would need to be correlated to a lower degree than these test-retest coefficients.

Third, the present study revealed an extremely large association between maximizing tendencies and Lack of Readiness scores. This finding suggests that when clients exhibit career indecision that takes the form of a lack of readiness, counselors may choose to utilize interventions that seek to increase maximizing tendencies. 


\section{Limitations and Future Research Directions}

Whereas this study has many merits and adds considerably to the psychometric research of a relatively new measure, it is not without its limitations. First, although I tried to make the college student and non-college samples as similar as I could demographically, some notable differences remained. The non-college sample was significantly older than the college student sample. In addition, a larger percentage of women comprised the college-student than the noncollege sample. Future research should seek to narrow these demographic differences in order to more definitively conclude that the differences observed can be attributed to the variable (college vs. non-college) of real interest.

Second, only one measure of maximization tendency was used. Future research should use other measures of maximization, such as the Maximization Scale (MS; Schwartz et al., 2002) to validate the relation between the tendency to be a satisficer and scoring highly on the Lack of Readiness factor of the CIP-65. Instead of using generalizable items like the MTS (e.g., "I don't like having to settle for good enough"), the MS contains specific examples. Additionally, only a modest correlation has been found between these two measures of maximization $(r=.40$;

Giacopelli et al., 2013). Furthermore, unlike the MS, the MTS has not been found to correlate with life (dis)satisfaction (Diab et al., 2008).

Third, before the CIP-65 should be used widely in practice, some form of predictive validity should be established. For example, a longitudinal study using the CIP-65 to predict future joblessness or unhappiness with one's career would be a useful endeavor. Construct validity and reliability are somewhat worthless if the scores on a measure cannot accurately predict future behaviors or attitudes. 
Finally, there is something to be said about an emic approach to career indecision research, rather than the etic approach the present study took. Rather than testing the fit of a model and measure developed for college students in a different population, perhaps developing a new measure within a non-college culture is warranted. By relying on the CIP-65 or any other measure that was developed from within a college culture, we might be missing important information about career indecision in non-college individuals.

\section{Conclusion}

This study furthered the psychometric research for the CIP-65 and found evidence to support its use in practice and further research. Although the hypothesized factor structure was found in both college student and non-college samples, significant differences emerged in the way non-college participants interpreted several items. Because of these differences, career counselors and related professionals should use the CIP-65 with these limitations in mind in noncollege populations. A very strong association between maximization tendencies and one of the four factors of the CIP-65 was revealed, and although future studies should verify these results, this finding could open a potentially useful and intriguing avenue in the field of career indecision. 


\section{REFERENCES}

Abrams, M. D., Lee, I. H., Brown, S. D., \& Carr, A. (2015). The career indecision profile: Measurement equivalence in the United States and South Korea. Journal of Career Assessment, 23, 225-235. doi:10.1177/1069072714535028

Abrams, M. D., Omarsdottir, A. O., Bjornsdottir, M. D., Einarsdottir, S., Martin, C., Carr, A., ... Rector, C. (2013). Measurement invariance of the career indecision profile: United States and Iceland. Journal of Career Assessment, 21, 469-482. doi:10.1177/1069072712475181

Bandura, A. (1995). Self-efficacy in changing societies. Cambridge, England: Cambridge University Press.

Binning, J. F., \& Barrett, G. V. (1989). Validity of personnel decisions: A conceptual analysis of the inferential and evidential bases. Journal of Applied Psychology, 74, 478-494.

Brown, S. D., Hacker, J., Abrams, M., Carr, A., Rector, C., Lamp, K., Telander, K. J., \& Siena, A. (2012). Vallidation of a four-factor model of career indecision. Journal of Career Assessment, 20, 3-21. doi: 10.1177/1069072711417154

Brown, S. D., \& Rector, C. C. (2008). Conceptualizing and diagnosing problems in career decision-mking. In S. D. Brown \& R. W. Lent (Eds.), Handbook of counseling psychology ( $4^{\text {th }}$ edition., pp.392-407). New York, NY: Wiley. 
Brown, S. D., \& Ryan Krane, N. E. (2000). Four (or five) sessions and a cloud of dust: Old assumptions and new observations about career counseling. In S. D. Brown \& R. W. Lent (Eds.), Handbook of counseling psychology ( $3^{\text {rd }}$ ed., pp. 740-766). New York: Wiley

Buhrmester, M., Kwang, T. \& Gosling, S. D. (2011). Amazon's mechanical turk: A new source of inexpensive, yet high-quality data? Perspectives on Psychological Science, 6, 3-5. doi: 10.1177/1745691610393980

Carr, A., Rossier, J., Rosselet, J. G., Massoudi, K., Bernaud, J-L, Ferrari, L., ... Roche, M. (2013). The career indecision profile: Measurement equivalence in two international samples. Journal of Career Assessment, 22, 123-137. doi: 10.1177/1069072713492930

Chartrand, J. M., \& Nutter, K. J. (1996). The Career Factors Inventory: Theory and application. Journal of Career Assessment, 4, 205-218.

Chartrand, J. M., Robbins, S. B., Morrill, W. H., \& Boggs, K. (1990). Development and evaluation of the Career Factors Inventory. Journal of Counseling Psychology, 37, 491501.

Cobb-Clark, D. A., \& Schurer, S. (2012). The stability of big-five personality traits. Economics Letters, 115, 11-15.

Costa, P. T., Jr., \& McCrae, R. R. (1992). NEO-PI-R: Professional manual. Odessa, FL: Psychological Assessment Resources.

Cronbach, L. J. (1970). Essentials of psychological testing (3 ${ }^{\text {rd }}$ ed.). New York: Harper \& Row. 
Diab, D. L., Gillespie, M. A, \& Highhouse, S. (2008). Are maximizers really unhappy? The measurement of maximizing tendency. Judgment and Decision Making, 3, 364-370.

Donnay, D. A. C., Morris, M. L., Schaubhut, N. A., \& Thompson, R. C. (2005). Strong Interest Inventory ${ }^{\circledR}$ Manual. Mountain View, CA: CPP, Inc.

Foley, P., Kelly, M., \& Hartman, B. (2006). Career indecision. In J. Greenhaus, \& G. Callanan (Eds.), Encyclopedia of Career Development. (pp. 110-116). Thousand Oaks, CA: SAGE Publications, Inc. doi: http://dx.doi.org/10.4135/9781412952675.

Gati, I., Krausz, M., \& Osipow, S. H. (1996). A taxonomy of difficulties in career decision making. Journal of Counseling Psychology, 43, 510-526.

Giacopelli, N. M., Simpson, K. M., Dalal, R. S., Randolph, K. L., \& Holland, S. J. (2013). Maximizing as a predictor of job satisfaction and performance: A tale of three scales. Judgment and Decision Making, 8, 448-469.

Goodman, J. K., Cryder, C. E., \& Cheema, A. (2013). Data collection in a flat world: The strengths and weaknesses of mechanical turk samples. Journal of Behavioral Decision Making, 26, 213-224. doi: 10.1002/bdm.1753

Hacker, J., Carr, A., Abrams, M., \& Brown, S. D. (2013). Development of the career indecision profile: Factor structure, reliability, and validity. Journal of Career Assessment, 21, 32-41. doi: 10.1177/1069072712453832

Hartman, B. W., Fuqua, D. R., \& Jenkins, S. J. (1986). The reliability/generalizability of the construct of career indecision. Journal of Vocational Behavior, 28, 142-148. 
Hartman, B. W., Utz, P. W., \& Farnum, S. O. (1979). Examining the reliability and validity of an adapted scale of educational-vocational undecidedness in a sample of graduate students. Journal of Vocational Behavior, 15, 224-230. doi: 0001-8791/86

Henry, P. J. (2006). College sophomores in the laboratory redux: Influences of a narrow data base on social psychology's view of the nature of prejudice. Psychological Inquiry, 19, 49-71. doi: 10.1080/10478400802049936

Holland, J. L., \& Holland, J. E. (1977). Vocational indecision: More evidence and speculation. Journal of Counseling Psychology, 24, 404-414.

Hu, L. \& Bentler, P. M. (1999). Cutoff criteria for fit indexes in covariance structure analysis: Conventional criteria versus new alternatives. Structural Equation Modeling: A Multidisciplinary Journal, 6, 1-55. doi:10.1080/10705519909540118

Iyengar, S. S., Wells, R. E., \& Schwartz, B. (2006). Doing better but feeling worse: Looking for the "best" job undermines satisfaction. Psychological Science, 17, 143-150. doi: 10.1111/j.1467-9280.2006.01677.x

Jones, L. K. (1989). Measuring a three-dimensional construct of career indecision among college students: A revision of the Vocational Decision Scale-The career decision problems. Journal of Counseling Psychology, 36, 477-486.

Kahn, J. H. (2006). Factor analysis in counseling psychology research, training, and practice: Principles, advances, and applications. The Counseling Psychologist, 34, 684-718. doi: $10.1177 / 0011000006286347$ 
Kelly, K. R., \& Lee, W. C. (2002). Mapping the domain of career decision problems. Journal of Vocational Behavior, 61, 302-326.

Kelly, K. R., \& Pulver, C. A. (2003). Refining measurement of career indecision types: A validity study. Journal of Counseling and Development, 81, 445-454.

Kline, R. B. (2010). Promise and pitfalls of structural equation modeling in gifted research. In B. Thompson \& R. F. Subotnik (Eds.). Methodologies for conducting research of giftedness (pp. 147-169). Washington, DC: American Psychological Association.

Lindholm, J. (2006). Deciding to forgo college: Non-college attendees' reflections on family, school, and self. The Teachers College Record, 108, 577-603.

MacCallum, R. C., Browne, M. W., \& Sugawara, H. M. (1996). Power analysis and determination of sample size for covariance structure modeling. Psychological Methods, $1,130-149$.

McBurney, D. H., \& White, T. L. (2010). Research Methods. Belmont, CA: Wadsworth

Meade, A. W., Johnson, E. C., \& Braddy, P. W. (2008). Power and sensitivity of alternative fit indices in tests of measurement invariance. Journal of Applied Psychology, 93, 568-592.

Osipow, S. H. (1980). Career indecision scale: Manual. Odessa, FL: Psychological Assessment Resources

Osipow, S. H. (1986). Career indecision scale: Manual. Odessa, FL: Psychological Assessment Resources. 
Osipow, S. H., Carney, C. G., \& Barak, A. (1976). A scale of educational-vocational undecidedness: A typological approach. Journal of Vocational Behavior, 9, 233-243.

Pascarella, E. T., \& Terenzini, P. T. (2005). How college affects students: A third decade of research. San Francisco, CA: Jossey-Bass.

Paolacci, G., \& Chandler, J. (2014). Inside the turk: Understanding mechanical turk as a participant pool. Current Directions in Psychological Science, 23, 184-188. doi: $10.1177 / 0963721414531598$

Quick facts about Illinois State. (2014). Retrieved from illinoisstate.edu/quickfacts/

Ross, J., Irani, I., Silberman, M. Six, Zaldivar, A., and Tomlinson, B. (2010, April). Who are the Crowdworkers?: Shifting Demographics in Amazon Mechanical Turk. Paper presented at the ACM CHI Conference, Atlanta, GA.

Saka, N., Gati, I., \& Kelly, K. R. (2008). Emotional and personality-related aspects of career decision-making difficulties. Journal of Career Assessment, 16, 403-424. doi: $10.1177 / 1069072708318900$

Salomone, P. R. (1982). Difficult cases in career counseling: Pt. II. The indecisive client. Personnnel and Guidance Journal, 60, 496-499.

Schwartz, B., Ward, A., Montersso, J., Lyubomirsky, S., White, K., \& Lehman, D. R. (2002). Maximizing versus satisficing: Happiness is a matter of choice. Journal of Personality and Social Psychology, 83, 1178-1197. doi: 10.1037//0022-3514.83.5.1178 
Sears, D. O. (1986). College sophomores in the laboratory: Influences of a narrow data base on social psychology's view on human nature. Journal of Personality and Social Psychology, 51, 515-530.

Simon, H. (1955). A behavioral model of rational choice. Quarterly Journal of Economics, 69, 99-118.

Tellegen, A., \& Ben-Porath, Y. S. (2011). MMPI-2-RF (Minnesota Multiphasic Personality Inventory-2 Restructured Form): Technical manual. Minneapolis, MN: University of Minnesota Press

Tien, H. S. (2005). The validation of the Career Decision-Making Difficulties Scale in a Chinese culture. Journal of Career Assessment, 13, 114-127.

U.S. Department of Labor, Bureau of Labor Statistics. (2014, May 8). 65.9\% of 2013 high school graduates enrolled in college. Retrieved from http://www.bls.gov/opub/ted/2014/ ted_20140508.htm

Vandenberg, R. J., \& Lance, C. E. (2000). A review and synthesis of the measurement invariance literature: Suggestions, practices, and recommendations for organizational research. Organizational Research Methods, 3, 4-69.

Whiston, S. C., Brecheisen, B. K., \& Stephens, J. (2003). Does treatment modality affect career counseling effectiveness? Journal of Vocational Behavior, 62, 390-410. 